\title{
Principled Entrepreneurship And Shared Leadership: The Case Of TEOCO (The Employee Owned Company)
}

Thomas J. Calo, Salisbury University, USA

Olivier Roche, Salisbury University, USA

Frank Shipper, Salisbury University, USA

\begin{abstract}
This case describes a unique corporate culture, focused on employee ownership and employeecentered Human Resource practices, which fosters employee loyalty and motivates employee focus on organization objectives. The organization's CEO and senior management team discuss in detail the company's development strategy, the concept of shared leadership, and its strategic focus on Human Resource Management. Also emphasized is how the organization's recent partnership with a private equity firm, and its acquisition of an international organization of similar size, may change TEOCO's culture and its business model.
\end{abstract}

Keywords: Employee Ownership; Private Equity Firm; Shared Leadership; Corporate Culture; Strategic Human Resource Management

\section{INTRODUCTION}

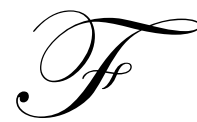

airfax, October 6, 2009. Atul Jain, founder of TEOCO, a provider of specialized software for the telecommunications industry, had been meeting all day to finalize a partnership agreement with TA Associates, a private equity firm. For Atul, the pace of activities had been relentless on this special day. ${ }^{1}$ By all accounts, the last 12 hours had been hectic but the closing of the transaction was a success. The event had started with back-to-back meetings between TEOCO's senior management and their new partner's representatives and had culminated with the usual press conference to mark the occasion. The senior management teams of both organizations announced to the business community that TA Associates [TA] had made a minority equity investment of $\$ 60$ million in TEOCO. It was indeed a memorable day, the culmination of intense and uneven negotiations between two organizations that did not have much in common except for deep industry knowledge and a shared interest in seeing TEOCO succeed.

This new partnership marked the end of a marathon, but Atul did not feel the excitement that usually comes with crossing the finish line. It was late and he was tired. Back in the quiet of his office, he reviewed, once again, the draft of the press release relating the day's event. As he read the various statements captured from the meetings, he still had the uneasy feeling that comes with making life-changing decisions when one does not have all the required information. There were so many unknowns. Partnering with the right investor, like many other entrepreneurial endeavors, was not a decision made in a vacuum. It was all about good timing, cold analysis, gut feeling and luck; the latter was last but by no means least. Despite all the uncertainty, Atul felt that this was a worthy endeavor.

Atul had come a long way since his humble beginnings in India and a lot was at stake, not only for him but also for the 300 employees of the company. The TEOCO enterprise had been a successful business endeavor and at the same time a very personal journey. What had begun as a result of frustration with his old job in Silicon Valley 15 years ago had become one of the fastest growing businesses in the telecom software industry; and the fast pace of

\footnotetext{
${ }^{1}$ All employees are referred to in this case by their first name including the CEO because that is standard practice at TEOCO.
} 
the company's development had not gone unnoticed. For quite some time now, TEOCO had been on the "radar screen" of investors looking for high-growth opportunities. However, Atul had never cultivated a relationship with potential external investors; he had remained congruous with his long-held business beliefs that an alliance with external financiers was rarely in the best interest of a company and its employees.

Atul [CEO \& Chairman]: "I am often asked why we didn't approach an investor for money or seek venture capital. I have two answers to this question. My first answer is: that's not our way of doing business. I believe that every entrepreneur must aspire to be debt-free and profitable from the very first day. My second answer is: nobody would have given me the money even if I had asked! I also had a fear - that external investment might impact the culture and values that I wanted TEOCO to promote and cherish. I wanted to steer the TEOCO ship along a very different course. My dream was to set up an enterprise based on a model of shared success. TEOCO's success wouldn't just be my success; it would be our success. TEOCO wouldn't just have one owner; it would be owned by each of its employees - who would therefore be called employee owners."

But several months earlier, events had taken an unexpected turn; unsolicited financiers approached TEOCO once again, this time offering to invest a substantial amount of capital. Still, Atul was reluctant to engage in negotiations with a party that, as far as he knew, did not share TEOCO's values.

Atul: "[In the early days]we took a conscious decision not to accept venture capital. I have always had a healthy disdain for venture capital because it numbs the entrepreneur's competitive edge and enfeebles him. I still remember TEOCO's early battles with [competitors] Vibrant and Broadmargin and how difficult it was for us to compete with all that extra money flowing into the rival's coffers. But we took the hard road - and survived.... What, then, went wrong with Broadmargin or Vibrant? If I have to over-simplify, I'd say that both were done in by venture capital. $V C$ is an impatient master; it forces you to always go for the home run, and always push hard on the gas. With certain kinds of businesses this works; indeed, it might be the only way. Think of Google: their business space is so vast that only continuous and unbridled growth can sustain the venture. But TEOCO's space is very different; there is no exponential growth here that everyone can go chasing...I would guess that the size of the telecom Cost Management business is no larger than $\$ 100$ million per year; so to survive you have to be patient and play your cards carefully. This isn't the place to be if you are in a tearing hurry to grow.... While this strategy of focusing on niche markets significantly limits our market potential, it does keep the sharks away. The big companies are not bothered by niche products for telecom carriers; they don't want to swim in small ponds."

Atul's comment reflected the situation a few years ago; TA's recent partnership offer was made in a new context. In this rapidly-changing industry, there are constantly new directions in technology and the landscape continually shifts. The industry, consolidating quickly, required that in order to remain a viable player, TEOCO would have to change gears - sooner rather than later.

Until now, the primary focus of the company had been on the North American telecom carriers. However, with the anticipated consolidation of the telecom industry in North America, TEOCO needed to focus on international expansion. In addition, to leverage TEOCO's deep expertise in cost, revenue and routing, the company would soon need to fish "outside the pond" and enter the global business support system / operations support system (BSS/OSS) market. Here, TEOCO could find itself in competition with much larger players and it would be valuable to have a strong financial partner.

Indeed, the company had reached an important threshold in its organizational development. But if TEOCO was at a crossroads, so was its founder. Atul was in his late forties and he was not getting any younger. In this industry Atul had known many entrepreneurs who, like himself, had rapidly grown their businesses only to find out that "you are only as good as your last call." For a few of these entrepreneurs, one or two poor decisions had triggered a descent that had been as swift as their earlier ascent and they ended up with very little to show for their efforts. These were the intangibles. During rare moments of quiet reflection, Atul realized that his "risk return profile" had changed imperceptibly over time. Having all his eggs in the same basket and going for all or nothing had been fun in his mid- thirties when everything was possible, but it would be much less so in his early fifties when starting from scratch would be a very unappealing scenario for Atul and his family. Furthermore, he felt an obligation to create liquidity for the employees who had supported him on this fifteen year journey and had their 
own dreams and goals. At the end of the day, any business has only three exit options: it could get listed, be sold or go bankrupt! And the latter option is not particularly appealing.

It was in this context and mindset that he had agreed to listen to what TA Associates had to offer. Founded in 1968, TA had become one of the largest private equity firms in the country. The company was managing more than $\$ 16$ billion in capital by 2009 and it had an extensive knowledge of the industry. Atul was impressed by TA's approach, its willingness to take a minority position, and Kevin Landry, Chairman and the "spirit" of TA. This private equity firm not only managed capital; it also had impressive network of relationships. In addition, TA executives had been adamant that Atul remain in charge, and he was keen on continuing as the controlling shareholder. The fund would appoint two board members [see Appendix 1] but TEOCO's current management team would still lead the company as they had in the past.

Reviewing the details, Atul could not spot any flaws in the logic of the transaction. It was neither a marriage of love nor a "shotgun wedding," just a pragmatic alliance between two companies with complementary skills and resources at a time when such alliance was valuable to both parties: TA looking for a good investment and TEOCO shareholders looking for partial liquidity. As Atul re-read the press release and a few of his quotes, he reflected that he meant every word.

Atul: "We are pleased to welcome TA as our first institutional investor. As a company that has avoided external capital for 15 years, we are delighted to find a partner that will strengthen TEOCO without changing the culture of our organization. We see this as the beginning of a new phase in TEOCO's history where we look to add even greater value to communications service providers worldwide."

This was definitively a new era and there would be no turning back. For better or for worse, this partnership had to work. Atul made minor corrections to the wording of the document and authorized its release.

\section{COMPANY BACKGROUND AND ACTIVITIES}

TEOCO's predecessor, Strategic Technology Group (STG), was founded as an S corporation in 1994. The company's initial focus was to provide high quality consultancy for IT projects. STG's first clients included Mobil, Siemens, Cable \& Wireless, SRA, TRW and Freddie Mac. The company started operations in April 1995 and three years later, in March 1998, the company name was changed to TEOCO (The Employee Owned Company). At the same time, TEOCO made the strategic decision to shift its business from consultancy to product development and to focus on the telecommunications industry. This was achieved through the acquisition of a fledgling software product that processed invoices of telecom payables. BillTrak Pro would ultimately become TEOCO's best-selling network cost management software.

Subsequently, the company grew rapidly. As the number of employees exceeded 75 , the maximum numbers of shareholders an $\mathrm{S}$ corporation can have, the company changed its status to a $\mathrm{C}$ corporation to enable a broad based employee ownership. Over the years preceding the burst of the "Dot.com" bubble, TEOCO not only expanded its client base for its basic products but also invested substantial amounts of capital in three startups. These entities were: netgenShopper.com for online auctions; Eventrix, an event planning portal; and AppreciateYou.com to support employee retention. These internet startups functioned as separate entities, each at their own location, with their own business goals and core values, managed by different entrepreneurs/managers; at the same time, they each relied on TEOCO's cash flow for their development.

Ultimately, none of these ventures emerged as viable businesses and this left TEOCO in a difficult financial situation. As a result, TEOCO registered its first year of losses in 2000.

Atul: "This failure was devastating, but also a humbling experience. I learned the hard way that no entrepreneur can survive inside a technology incubator. We had to pay a price for all these transgressions... Our revenues were still impressive, but the money in the bank was dwindling rapidly... We were truly caught in deep and dangerous waters. I have often wondered what went wrong. It wasn't as if we made one big mistake...I guess we just took our 
eyes off the ball. Somewhere along the way, we lost our focus; we tried to do too many things at the same time and ended up getting nothing right. We had to quickly get back to our knitting. The question was: how?"

Under Atul's leadership, TEOCO made the judicious decision to refocus its activities on its core industry expertise and its largest clients. To achieve this, the organization solidified its position in the telecom sector by improving its services and developing new products. In 2004, research and development efforts resulted in the patented XTrak technology which today represents the core of the company's invoice automation solution. In addition, TEOCO was able to migrate from software licensing to the far more lucrative software-as-a-service model. Instead of a fixed licensing fee, the company charged a recurring monthly fee based on the volume of data processed for each client. As the recurring revenue model took hold, it became much easier to grow revenues from year to year and improve company's profitability.

In 2006, TEOCO acquired Vibrant Solutions, bringing in cost management and business intelligence assets with its 24 employees. Ultimately this resulted in the important development of TEOCO's SONAR solution for cost, revenue and customer analytics. Finally, in 2008, Vero systems was acquired, adding routing management and its 36 employees to the repertoire of communication service provider solutions.

This stream of acquisitions and internal development left TEOCO with a staff of about 300 employees and a portfolio of three major activities: cost management, least cost routing and revenue assurance.

\section{Cost Management}

Cost management solutions include invoice automation and payable processing. Powered by XTrak, TEOCO's invoice automation solution processes over 1,000,000 invoices annually. This facilitates the audit and analysis of billions of dollars in current billings due to each telecom company. While the usual scanning of paper bills relies on optical character recognition technologies that routinely require hands-on intervention to correct misrepresented characters on complex invoices, the XTrak technology mines the original formats which produced the paper to create files for loading into cost management solutions. By eliminating the tedious, costly and errorprone task of manual invoice data entry, telecom companies increase productivity and reduce costs by increasing the number of disputes filed and resolved and by reducing late-payment charges. In addition, TEOCO also processes "payables" on behalf of clients by managing the full life-cycle of invoice payment, including account coding, management review and payment reconciliation. TEOCO's employees audit client invoices, comparing rates, inventory and usage with other source data to identify and recover additional savings. Finally, the company manages disputed claims on behalf of its clients from creation through resolution. TEOCO has the technical capability to capture all correspondence between parties and can review and track every claim to resolution.

With regard to cost management, it is worth noting that the Sarbanes-Oxley Act of 2002 requires every listed company to implement a reliable reporting system. TEOCO's services support this compliance by improving the details and timeliness of the reports generated by/for telecom companies. TEOCO's rapid development in this area coincided with a market need that was augmented by the legal requirements imposed by the Act.

\section{Least Cost Routing}

TEOCO's routing solutions help telecom companies determine the optimal route between two customers with regard to cost, quality of service and margin targets. Capable of supporting multiple services and various networks, the company is able to monitor CDRs (Call Detail Records) in near real time to identify bottlenecks, reroute traffic and improve the quality of services for greater satisfaction of its clients' customers.

\section{Revenue Assurance}

Communications service providers can lose $5-15 \%$ of gross revenue due to revenue leakage. TEOCO's SONAR solution is an industry first in supporting switch-to-bill reconciliation. TEOCO combines its specialized industry expertise with high-capacity data warehouse appliances to create a unified CDR and makes a high volume of current and historical CDR data available on a single platform for in-depth analysis. This helps telecom 
companies uncover billing discrepancies, detect fraudulent behavior, reveal usage patterns, understand customer profitability, conduct margin analysis, and determine the financial viability of reciprocal compensation agreements.

\section{INDUSTRY LANDSCAPE: Continuous Change}

\section{Competitors}

TEOCO operates in a fragmented and highly competitive industry. Appendix 2 lists its competitors in each of the three major business segments. TEOCO operates mostly in North America; therefore, the main competitors in the cost management segment are Razorsight, Connectiv and Subex. These same companies compete for revenue assurance, as well as others such as cVidya and Wedo. Finally, in the least cost routing segment, TEOCO faces a different set of competitors: Pulse Networks, Global Convergence Solutions and Telarix.

Brian [Marketing \& Communications Department]: "So [from the customer's point of view] what we bring to the table is just end-to-end solutions that reach all of these different categories. While we still compete with certain people, it's on a specific product; not across the board."

Indeed, with the possible exception of Subex, none of the above competitors operate in the same three business segments as TEOCO; and Subex does not provide a domestic least cost routing in North America. Since TEOCO derives $50 \%$ of its revenue from cost management and $25 \%$ from revenue assurance, Razorsight and Subex could be considered TEOCO's main business competitors. Faye summarizes TEOCO's current market position.

Faye [General Manager/Account Management]: “...In North America, we dominate the cost management space. We've got a decent lock on least cost routing, which is a very operational and technical function that bridges between network and finance."

One of the ways TEOCO differs from most of its VC backed competitors is its focus on internal cost management. This manifests itself in two different ways. The management begins the year by making a conservative revenue plan for the year. The company then manages its expenses to be a fixed percentage of the projected revenues. Investments in Sales, Marketing, and $R \& D$ are adjusted throughout the year to ensure that expenses stay with-in the pre-defined limits. The second way cost management manifests itself is how the cost of each individual transaction is closely managed and monitored whether it be purchasing hardware, leasing office space, renewing supplier contracts, recruiting new employees, or planning business travel.

One of the consequences of this strong discipline of cost management is that TEOCO is consistently profitable, something most of its competitors struggle to accomplish. This enables the company to focus its energy on clients and innovation.

\section{Clients}

TEOCO operates in an industry where clients are known and clearly identifiable. One of the key reasons clients buy from TEOCO is because its solutions have a strong ROI (Return on Investment). In other words, TEOCO's products quickly pay for themselves and then begin to generate profits for the companies that subscribe to them.

Faye: "The telecommunication space is who we sell to exclusively, and within that space, we have a relatively known and discreet customer list or target list, if you will. We don't sell cookies. Not everybody's going to buy what we're selling...I know who those customers are and I can identify groups within that addressable market that fall into natural tiers. So either because of their size or because of the market that they cater to, themselves, whether they're wireless or wire line or whether they're cable companies, I can identify who they are and then try to focus products and services that I think will best meet their needs."

There are four telecom companies that drive about $65 \%$ of TEOCO's domestic revenue: Verizon, Sprint, AT\&T and Qwest; these are the "platinum" accounts. For obvious reasons, they get a lot of attention from both the 
engineering and product delivery standpoints. Thirty-five other companies, including Cricket, Global Crossing, Metro PCS, Level 3 and Bell Canada, account for the remaining balance of revenues.

TEOCO, like most of its competitors, is client-centered. Smooth customer interactions are not only critical to increase sales and garner new relationships but also to develop new products. Over the years, most of the ideas for new products or improvements to existing products have come out of discussions with customers.

Hillary [Marketing \& Communications Department]: "Our number one avenue for receiving customer feedback is our TEOCO summit, our annual user meeting... where customers are able to talk one-on-one with not only TEOCO representatives but also with other customers to learn what they are doing... and then circling back with TEOCO."

Initially, TEOCO used its generic products, either developed in-house or brought in via acquisitions, to start relationships with new clients. More recently, however, the company has innovated solutions driven by specific clients. These, in turn, are adjusted to suit the needs of other clients. Dave describes this "evolutionary loop."

Dave [Software Architect]: "With our first product [BillTrak Pro], we sold it to a number of different carriers resulting in a broad footprint of wireline and wireless carriers. Then we had account managers engage with our customers, and it's through conversations with our existing customers, generally, that the ideas for the next set of products come out...More recently, I'd say that most of our products are customer-driven, so what will happen is we'll have someone in the company that will identify a need at a specific customer. Then, we'll enter into some kind of partnership with them, whether we'll develop the application specifically to their needs and then work to resell that and make it useful to other customers as well."

\section{GROWTH STRATEGIES}

\section{TEOCO’s Product Strategy: “Spidering” Through Clients' Organizations}

Since the number of clients is limited, two other ways to grow the business are cultivated. A company like TEOCO can either "productize" its current services or acquire a competitor with a different client base and cross-sell its products.

Faye: “....But for the products we're selling, if we have two new sales a year, that's significant ... maybe you could squeak out a third in a good year. So the majority of the sales growth really comes from existing accounts...most of the growth though is coming from those large platinum accounts. Those are the ones that have money to spend and where we're driving products, driving solutions, trying to help them tell us or help them identify where they have needs. The other way to grow the business is to acquire companies that have a different business and then cross-sell services. For instance, with the Vero acquisition, we added another 'vertical' line of business [least cost routing]...And then Vero had a relatively separate client base... so we were able to cross-sell products into each other's companies' portfolio of clients [i.e., TEOCO's clients buying least cost routing services and Vero's clients buying cost management products]."

Faye joined the company in March 2010, a few months after the TA's investment in TEOCO with a charter to grow TEOCO's revenues with its smaller customers. With Faye in position, the company became more market-driven and far more aggressive in cross-selling its services and products among the three main lines of business. As well, it adopted a more cohesive approach to expand the client base, including leveraging its reputation for excellence and for having the technical ability to solve problems across various business segments.

Faye: “We're 'spidering' through [our clients'] organizations. With each additional organization that we enter into, the stickier we become. Our software products run the gamut from mission critical to nice-to-have. And the more mission criticals and nice-to-haves we get, the stickier we are in that organization, in all the organizations....[For instance] ...I'm not going outside AT\&T, but I have - instead of two customers at AT\&T, I now have ten. And they're distinctly different sales each time." 


\section{TEOCO's Acquisition Strategy}

For the first ten years of TEOCO's existence, Atul had built the business based on the premise that growth had to be organic and financed through internal cash flow. To some extent, his views on acquisition were consistent with his opinions about external financing from VCs and private funds. For Atul, acquisition and growth financed by external funds represented a risky development strategy that could dilute a company's culture.

However, as noted earlier, internal growth through innovation had been slow and limited in scope. Crossselling products between vertical lines of business coming from acquired companies with a different client base offered far more potential for the organization's growth. Therefore, it was just a matter of time before TEOCO would decide to "experiment" with acquisitions:

Atul: "When we started building TEOCO, I was very focused on organic growth. I felt that acquisitions tend to dilute culture and values. But then we happened to acquire a company called Vibrant Solutions (in 2006) and that acquisition went so phenomenally well, it gave us a lot of encouragement. The people were great, the product was solid and the client relationships were very valuable. They integrated well into our company and into our culture. We felt it made TEOCO a much stronger company. We had just broadened from cost management into revenue management before we acquired Vibrant, but I don't believe we would have been as successful in delivering on that without the expertise of the people that came from that acquisition."

The subsequent acquisition of Vero in 2008 brought TEOCO closer to the network and strengthened its position in the market place, particularly with the larger customers. This reinforced TEOCO's belief that acquisition of carefully selected targets should be a key component of its overall growth strategy.

Atul: "So at the end of that I said to myself maybe my narrow-minded thinking about acquisition diluting the culture was wrong, that in fact, if you do it right, you have an opportunity to strengthen the culture. ."

From these two positive experiences, Atul established guidelines for the kinds of companies to target when scanning the market for future acquisitions. TEOCO would look for companies that:

- $\quad$ Had people with deep industry expertise;

- $\quad$ Offered solutions/products that the marketplace valued;

- $\quad$ Had a solid customer base that had been established over time;

- $\quad$ Offered potential synergies with current products/services offered by TEOCO;

- $\quad$ Had not been able to develop their full potential due to poor management;

- $\quad$ Had a manageable size to facilitate their integration into TEOCO's current businesses.

Atul: "One thing you will see in the companies we acquire is that before the acquisition those companies were not running that smoothly. If they were, perhaps they wouldn't be up for sale or be affordable. We tend to acquire companies that present a challenge but also an opportunity for us to improve the business and make it much stronger and more valuable."

What enabled TEOCO to successfully integrate Vibrant and Vero into its business? TEOCO brought to the table: 1) a solid core business that generated a positive and stable cash flow; 2) a well-established strength in cost management (not only for its clients but also for itself); and 3) a disciplined approach to the management of human resources. Indeed, TEOCO is conservatively managed and Atul is recognized by employees for his ability to select and retain the best while optimizing the use of the organization's human resources. TEOCO core strengths, when applied to the business of Vibrant and Vero, resulted in a bigger and better company.

\footnotetext{
${ }^{2}$ http://www.billingworld.com/articles/2010/09/teoco-ceo-reversal-on-acquisitions-complete.aspx

3 Ibid.

${ }^{4}$ http://www.billingworld.com/articles/2010/09/teoco-ceo-reversal-on-acquisitions-complete.aspx 


\section{TTI Acquisition Rationale: Going Global And Getting "Closer To The Network"}

In December 2009, TEOCO began to consider the acquisition of the company that would become in 2010 its biggest acquisition ever -TTI Telecom. TTI was an Israel-based global supplier of service assurance solutions to communications service providers. The company had 300 employees and was listed on NASDAQ (TTIL). Through this acquisition, TEOCO would gain access to wide array of intellectual property including a Mediation Platform, Fault Management and Performance Management Systems, and valuable expertise in 4-G and data-centric networks. Service assurance is important in a data environment because it reduces jitter and packet loss during the delivery of high value data transfer. To some extent, TEOCO's existing portfolio of services and products would expand on TTI's well-recognized expertise in the next generation network (i.e., 4-G). In addition, TTI had an international client base that offered the potential to cross-sell TEOCO's existing product lines. On August 2010, TEOCO completed the acquisition, thus taking a big step in a new direction which, as of this writing, has yet to show conclusive results, but is considered a positive move.

Atul (at the time of the TTI acquisition): "Our last acquisition was Vero Systems (in October, 2008) and that brought us one step closer to the network. We were doing least cost routing and in that world you are trying to help determine how to terminate calls in the most cost-effective manner. The Vero solution got us working with network players and got us into the switches. It became clear that the closer we got to the network, the better business value we could create. So we started looking for companies that have intellectual property and an international client base that would bring us even closer to the network. TTI [Telecom] really fit that bill for us. TEOCO has traditionally been focused on North America so we thought acquiring a company with an international client base was of value to us. Their solutions in fault management, performance management and service management all bring us closer to network and assuring Quality of Service. We are good at handling large volumes of data and deriving intelligence out of that data. And we convert that intelligence into business value. A lot of people can derive intelligence from data but they aren't able to create actionable intelligence that creates bottom line value. We think we will be able to improve the economics of the data TTI collects for our customers. It may be a little into the future, but we believe this acquisition positions us to get to that future." 5

\section{TTI Acquisition Challenges}

From a technical and marketing point of view, the acquisition of TTI represented a very logical move that would allow TEOCO to expand its business while remaining focused on telecom carriers. It fit many of the acquisition criteria that Atul had laid out (see prior section), but it also represented a substantial departure from previous acquisitions in three critical aspects: its size, its location and culture, and the means of its acquisition.

1. The Size of the Target Company: In terms of revenues, TTI was four to five times larger than the last acquisition made by TEOCO and this purchase effectively doubled the size of the organization. On that point, Atul was the first to recognize that TEOCO was entering uncharted territories.

Atul: "All the other acquisitions were small. We bought a company with 24 employees, we bought a company with 36 employees, and this time we bought a company with 300 plus employees. So, this is going to present a completely different challenge and I don't know what that is going to be because I haven't dealt with it. So, it's yet to come."

From the outset, and unlike prior acquisitions, TTI remained an entity that was managed separately. Therefore, one of the key issues to be addressed in the short to medium term would be the degree of integration between the two companies.

2. The Location and Culture of the Target Company: TEOCO had essentially been operating in the US, whereas TTI was located in Israel and was far more international in its operations. This created tremendous opportunities for marketing synergies and for cross-selling products to a different client base.

${ }^{5}$ http://www.billingworld.com/articles/2010/09/teoco-ceo-reversal-on-acquisitions-complete.aspx 
Faye: "So I see leveraging a lot of the existing sales and marketing resources in Israel. I mean they have a strong presence in Israel, but they're really European. EMEA is big. But also CIS, they do a lot in Russia. ... MTS is one of their customers, which is just a huge, huge Russian company. Internationally, it's a brand new client base into which we can cross-sell the least cost routing and probably not the cost management products because they don't translate outside of North America as well. But certainly the least cost routing products. Taking their products into the North American base is definitively something we can do. And as far as clients' crossover versus new, they have about ten North American customers, only four of whom are existing customers of ours."

At the same time, however, it also exposed TEOCO's business to a pool of larger competitors that competed on a global basis. TTI was "swimming in a different pond" in which blue chip companies with wellrecognized brands and deep pockets were aggressively marketing their services.

Faye: "We participate in a handful of shows, and again, that's expanding quite a bit this year because of the international presence and customer base...it's further complicated, though, by this acquisition of TTI because ... they are a very sales and marketing-centric company, and it's going to be interesting to see how the cultures meld. ... I see a lot of Advil for me between now and then. We're going to have to get there. Traditionally, TTI has gone to a lot of shows and they like to build brand new booths and spend hundreds of thousands of dollars for each of these shows on their presence there, and [at TEOCO] we don't do that."

Indeed, TEOCO's management was cost conscious and not prepared to invest heavily in shows and other marketing activities where Return on Investment (ROI) is difficult to measure. It was not evident how the two cultures would merge. TTI management might argue that substantial resources would be needed to compete in their market segment while TEOCO's management would probably take the position that overspending on marketing and poor cash-flow management were the reasons for TTI's financial problems prior to its acquisition.

3. The Means of Acquisition: One cannot understand the acquisition of TTI without first understanding how the alliance with TA changed the company's and CEO's ways of doing business, as well as their risk/return profile. To some extent TA gave TEOCO's management both the means and the incentives to take more risks. TA's involvement provided TEOCO with the credentials to approach financial institutions and increase the company's financial leverage to acquire a large target. It is one thing when a US\$50 million company approaches a bank to finance the acquisition of another company of equivalent size. It is quite another when a US $\$ 16$ billion equity firm with a substantial stake in the acquirer approves the transaction at the board level. Following TA's equity participation, no one ever asked TEOCO if they had the means to acquire TTI and complete the transaction. The legitimacy provided by TA's participation was essential for the financing of the acquisition of a listed company where time is of the essence.

Avi Goldstein [CFO]: “... Before TA came on board, taking debt was something that was not on the table. And when TA came on board and they asked us, 'Are you willing to take debt to finance acquisitions?' and we said, 'Yes'... And maybe without TA we wouldn't go after TTI because of the debt, not so much because of the size of TTI."

While providing the means to be more aggressive in TEOCO's growth strategy, the partnership with TA also reduced Atul's aversion to risk. It was the TA "push-and-pull" strategy (i.e., providing the financial means while reducing the acceptable risk threshold) that allowed this transaction to materialize.

Atul: "I haven't fully understood how the TA transaction has changed us. I think, over time, I will understand how it has changed us. All I can tell you is that I feel a degree of financial independence and I personally feel that it is more important for me to focus on making a greater difference for the world. I don't know that I could have supported this acquisition if I hadn't gotten liquidity because this acquisition had a much higher risk profile."

\section{COMPANY CULTURE AND PHILOSOPHY}

The background and evolution of TEOCO provide the context for exploring the unique way in which the organization functions, which in turn explains the basis for its success. Three different lenses provide the focus for this understanding: shared leadership; a culture of employee ownership; and human resources as a strategic 
function. These three characteristics have combined to contribute to TEOCO's success, as well as its competitive advantage.

\section{Shared Leadership}

The shared leadership team is comprised of three leaders of the organization with distinctly different, but complementary, skills and responsibilities. These leaders are Atul Jain (Chairman and CEO), Philip M. Giuntini (Vice Chairman and President) and John Devolites (Vice President and General Manager). [See Appendix 3]

Atul is the central figure in the story of TEOCO. By understanding Atul's background, philosophy of life, vision and style, the organization and its unique culture create a cohesive portrait.

Atul was born in India in the early 60's. He has an older sister and an older brother. His father was a midlevel civil servant in India, now retired. Both of his parents live with him and his family, which is customary in Indian culture. Atul is married and has three children. His intellect and abilities were identified at an early age. When he was a teenager, he was invited to attend the prestigious Indian Statistical Institute, known as one of the best schools in India for the study of statistics, which required that the young Atul move away from home to live in another part of the country.

Atul was raised in the Indian religion of Jainism, an important aspect of his background that shaped his view of people and organizations. While he does not wear his religion "on his sleeve," it is evident that his religious beliefs and upbringing have had a significant impact on his leadership style and the culture he has shaped within TEOCO. Atul does not go to temple and does not even pray, so in that sense he does not consider himself to be a religious person. On the other hand, he expressed that he has internalized the culture and religion and that it manifests in his thinking about business. Jainism is an ancient but minority religion in India, ${ }^{6}$ yet its influence far exceeds its size, as Jains represent some of the wealthiest Indians. Among its core beliefs are a philosophy of nonviolence towards all living things, vegetarianism, a strong belief in self-help and self-support, and a continual striving towards the liberation of the soul. These tenets can be seen in Atul as he believes that everyone is an "independent soul," and that consequently he "can't make you do anything that you don't want to do." What stands out is that this type of thinking is very uncharacteristic for a leader.

Atul: "As a CEO of the company, I understand that I have no control over anybody. I can't get anybody to do anything.... so I don't spend my time trying to control people... what I try to do is to conduct myself in a manner that may encourage people to work in a certain way. I can try to create an environment that is encouraging; an environment in which people wish to excel."

When he came to the United States it was not to be an entrepreneur but to study for a doctorate degree in Probability and Statistics. He describes himself as an "accidental entrepreneur." A disillusioning experience working for a Silicon Valley firm led him to reconsider his options. When commitments regarding future assignments and compensation were not honored, and he felt disrespected by the company's CFO, he became motivated to take the risk to establish his own company to prove that "you don't have to be an *\&\%\$\# in order to succeed in business". At the same time, this experience impressed upon him the importance of treating his future colleagues with fairness and respect.

Atul's personal leadership style, which is reflected by the organization, overall, is quite atypical, especially for an entrepreneur. Atul openly admits his shortcomings. While manifesting many of the traits of an entrepreneur, he sets himself apart by claiming that one of his greatest strengths is that he knows what he does not know. In fact, he even says "I know that I don't know how to run a business." In conjunction with his perceived shortcomings, he also believed that you create joy at work by sharing the decision making with others in the organization. The end result was his desire to establish a structure of shared leadership within TEOCO. He demonstrated this by

\footnotetext{
${ }^{6}$ Jainism is the least populous of the Indian religions; comprising approximately $0.5 \%$ of the population (Hindus represent approximately $80 \%$, Muslims approximately $12 \%$ and Christians approximately $3 \%$ ).
} 
establishing a "Steering Committee" of the senior employees within one year of the existence of the company, much prior to his association with Philip and John.

While there has been much discussion in the management literature on the potential value of shared leadership, few organizations have attempted it, and even fewer have utilized it successfully. In many respects, the notion of shared leadership is quite contrary to traditional beliefs about leadership in US organizations, which have strongly followed the military model of command and control. Atul's personal background and beliefs, coupled with a unique confluence of circumstances, have made shared leadership a major factor contributing to the success of TEOCO.

To understand why shared leadership at TEOCO was both possible and successful requires an understanding of the unique combination of personalities, leadership strengths and styles, along with the career and life circumstances - not only of Atul, the founder and CEO, but also the other two members of the leadership team; Philip, President; and John, General Manager.

Philip was a very successful, retired executive. Atul read an article in the Washington Post in September, 1998, that profiled Philip's retirement from American Management Systems (AMS) after 28 years. He contacted Philip, established a relationship with him, and eventually persuaded him to become a member of TEOCO's Board of Advisors. Within a year, Philip agreed to come out of retirement to serve as the Vice Chairman and President.

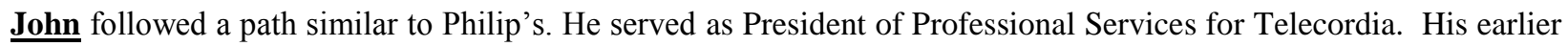
career experiences included executive positions at PriceWaterhouseCoopers, American Management Systems (AMS), and Booz Allen Hamilton. He became a member of the board in 2000, and in February 2004 he joined the company as a senior executive. In January 2005, he assumed the role of General Manager of its Telecom Business unit.

Personalities: In contrast with these two veteran executives, Atul was an entrepreneur with little or no experience in running a sizable business. However, he was a leader with a vision, strong intellect and a passion to build a successful company. In explaining why shared leadership works at TEOCO when it has not worked at many other organizations, Atul says that "I recognize that Philip and John are far more seasoned business professionals than me.... I go to them for guidance and advice and I will rarely do things that they do not agree with.” That said, Atul acknowledged that there are many challenges to shared leadership.

Atul: "The single biggest thing it requires on my part is to give up a ton of decision-making authority, and most people in a CEO chair are not willing to do that. I have to be subservient to John and Philip, and I'm happy to be...I feel that it is not in my personality to be authoritative... being forced to conduct myself in an authoritative manner is offensive to my soul."

John underlined the importance of personality in ensuring the success of shared leadership. While working at consulting firms, he had studied this concept and he commented, "I will tell you that when you look at the situation, it comes back to the individuals and the egos that they have. And if they have large egos, this would not work." When first asked about describing shared leadership at TEOCO, he responded by suggesting, "How about shared fate?"

Complementary Management Skills: The skill sets of these leaders are very complementary, and together form a powerful combination for organizational success. This was described separately, and consistently, by each of them. Atul excels at cost management and judging people.

Atul: "I really see my role as primarily focusing on culture and values and candidly I own all the decisions related to the ownership structure and internal management. However, I don't build anything and I don't sell anything."

Referring to Atul's strengths in cost management and people management, as opposed to direct customer interface, John noted that Atul rarely has customer interface, as Atul entrusts this responsibility to him. John's own skills and interests are focused on creativity and client relations. He sees his job as assembling people around clients 
and projects, and keeping customers happy. Finally, Philip is the one who makes it all happen. He is skilled at running a business that will endure, and has the organizational skills to free up Atul and John to do what they do best. As Philip describes, "We are all strong in a different place. Collectively, when we are together, we basically combine our strengths and eliminate our weaknesses... we do not compete with each other in our strong areas, and I think that is the key to it." John adds, "We would not be as successful if one of the other two of us weren't here." Atul shares the same view but from a different angle.

Atul: "I understand that I have certain strengths, and I tend to focus on playing to those strengths, and I have an understanding of what I'm not. ... I think incompetence can be valuable, if you know it. If you recognize that you don't know what to do, you're forced to ask others and the resulting collaborative environment has a power of its own."

Career and Life Circumstances: While personality and skills are important factors, it appears as well that life circumstances were a necessary pre-condition to the effectiveness of the collaborative model at TEOCO. In their own way, each of these leaders acknowledged that at a different time and place, shared leadership would not necessarily have been a model they would have liked or one with which they would have been successful. As John described, "I think you have to be at a point in your life where you're pretty comfortable with who you are." All three of these men, as a result of their career circumstances, have done well in their professional life. All of them have "builder" personalities; they derive a great deal of satisfaction from growing a business. For these leaders, the journey of growing TEOCO into a successful enterprise is as important as the end result.

\section{Culture Of Employee Ownership}

Atul has shaped the culture of TEOCO and ensures that it is continuously reinforced. This culture is founded upon the core values of the company. As he expresses it, "I define success as "living up to your values." Those values are rooted in a business philosophy he calls "principled entrepreneurship," which he defines as "a business where you have a set of values and you commit to living up to those values while trying to create business success." He further specifies, "They have to be a clear set of articulated values." In describing his success, he says that "what motivates me is to make as big a difference as I can for as many people as I can. And I was never in it solely for the money."

TEOCO has a clearly articulated set of core values [see Appendix 4] and a very distinct culture. Atul explains that the former were established even before he knew what the words "core values" meant. The initial slogan for the company was: "We'll take care of our employees, they'll take care of our clients, and that will take care of the business." He says that the actual articulation of and focus on "core values" began after he read a 1999 Inc. Magazine article based on the book Built To Last: Successful Habits of Visionary Companies, ${ }^{7}$ which caused him to ask, "Who are we?" rather than focusing primarily on "What do we want to be?"

A hallmark of TEOCO is the ownership culture that is embedded in the company. As an employee owned company, Atul wants all employees to buy and own TEOCO stock. Yet consistent with his overall philosophy of life, he does not believe he can make anybody buy the stock; he can only give them information and the opportunity to make that decision. He strongly believes that the environment created by employee ownership leads to better organizational performance and stronger employee commitment.

Atul: "I believe in the model of shared success. And I believe that if you share your success with the people that actually influence it and create it, then you create [something] extremely powerful. So, I'm fond of saying that TEOCO is a difficult company to beat - not because we are so good, but because it's tough beating a bunch of employee owners that feel so passionately about what they do."

\footnotetext{
${ }^{7}$ James C. Collins and Jerry I. Porras. New York: Harper Collins Publishers, 1994.
} 
$\mathrm{He}$ and the leadership team continuously seek to create and reinforce an "ownership culture" and have employees take an active part in ownership. Carrie (Director of Human Resources) has worked for TEOCO for seven years; previously she had worked for other organizations with stock programs that create an ownership stake in the company.

Carrie: "I would say that TEOCO is the first company I've worked for where it is as big of a deal. And we make it such a large component of the culture and we spend a ton of time from an HR perspective making sure people understand all the different elements of ownership, why we feel it's important to us, what different programs and mechanisms are out there to provide ownership and allow them to have an ownership stake in the company."

Hillary is an employee who has worked for TEOCO for five years in various professional positions, but has not worked at any other companies. She said she realized how much she appreciates the overall work environment at TEOCO when she compared her circumstances with friends. To describe the differences that may exist in working for an employee owned company as opposed to a traditional company, she said, "I think the employees here at TEOCO have a lot more knowledge about what's going on."

Dave, one of the earliest and longest-serving employees, when asked what employee ownership meant to him, said "I've got a stake in the game. My kid's college education is riding on this whole thing. There are no two ways about it.... I think a lot of the people in the company think that way."

Additionally, John, General Manager, explains further, “...It's keeping people motivated. It's keeping them focused. I think employee ownership helps us with some of those things... [It's] a very powerful ally when you're in a market that's got a lot of competition in it."

In addition to the organization's core values and corporate culture, the sense of ownership is reinforced through three distinct types of mechanisms: 1) Employees' involvement in the decision-making process; 2) Bonus and Stock Ownership; and 3) A Philosophy of Total Compensation.

\section{Employee Involvement In The Decision-Making Process}

The secret to making it work, according to Atul, is that "you have to create a culture of sharing in the decision-making process." The core values of TEOCO are manifested in the degree of employee involvement within the organization, as well as in the many significant ways employees contribute.

“All Hands Meeting:" At 11:00 a.m. on the first Thursday of every month, an "all-hands meeting" is held for all employees. This is a standing meeting, never moved or cancelled for any reason - one for US-based employees and one for employees in India. For those US-based employees who are geographically dispersed from corporate headquarters, a video feed goes out and an audio feed comes back so that questions can be posed from off-site locations. Each meeting lasts from 60 to 90 minutes and concludes with a pizza lunch.

These meetings have a structured format so that employees know what to expect. First, new employees are introduced; next, employee service anniversaries are acknowledged and celebrated (five, ten and 15 years' service awards are presented); and then there is a monthly drawing for the TeoStar Award. The second half of the meeting more formally introduces its principal objective: leadership providing a business update, as well as any news of particular interest to employees.

Once per quarter the meeting is devoted to detailed financial updates. This is described as an "open book" presentation; there is a review of the balance sheet and client revenues, an update from each line of business, and a discussion of new business prospects. Avi, CFO, elaborated that it is "not only one page of the $\mathrm{P} \& \mathrm{~L}$ and one page of the balance sheet; it's pretty extensive." Based on his prior experiences as a CFO, he said this is "like having a shareholder's meeting every quarter." Further, he specified that the company practices "open book management" and that the employees can see the books at any time. 
The February meeting each year is devoted to a presentation on the year-end financials, and employees are informed what percent of their target bonus they will receive. As of 2011, all employees with $3+$ years of service have received more than $100 \%$ of their target bonus for the last several years. Miscellaneous presentations are also made on topics of relevance, such as an update on the internal stock market.

Every meeting concludes with an open segment called "benefits and concerns." First, employees are encouraged to discuss any benefits received or positive experiences that have happened in the company. Mutual support and a form of company "cheerleading" is adopted. This is followed by a unique opportunity for any employee to raise any issue of concern. No question is considered out of bounds, and senior management is expected to respond openly and fully. The only ground rule is that every question must be phrased in the format of "I wish I knew...." For example, "I wish I knew why our financials were not as good this quarter," or "I wish I knew why we do not have a benefit such as... ." Atul said that this protocol ensures that concerns are presented in an impersonal and non-offensive manner; rather than being a challenge, each question focuses on looking for an explanation. He said that this approach has been "a game changer," "has really changed the tone of the meetings," and reflects the way in which owners would treat each other.

The A-Team: In addition to the opportunity to raise issues at the "all-hands meeting," a standing group of employee representatives meets each month. TEOCO's Advisory Team, simply called the A-Team, serves as an interface between the employee owners and the leadership team. The team is comprised of 12 people: eight full-time members and four alternates. Any employee can bring any issue to the A-Team, and the A-Team can bring any issue they choose to the leadership of the company. Similarly, the leadership can bring any issue to the A-Team. This is considered a mechanism to involve employees in the governance of the business; its chief function is to provide a voice to the employee-owners. The membership rotates each year, and outgoing members choose the incoming team. By design it is not intended to be composed of management, and the majority of the members are lower-level employees. As well, it intentionally includes a cross-section of members: single, married, from all geographic areas and from different levels within the organization.

\section{Bonus And Stock Ownership}

All employees receive an annual cash bonus. The program seems to function more like a traditional profit sharing plan, as it is not individual performance-related. The bonus pool equals $15 \%$ of pre-tax and pre-bonus profit of the company for the calendar year. The plan is designed to be entirely transparent. Each employee has a target bonus of $8 \%$ of base salary. The eligibility for the bonus percentage increases as the employee rises to different organizational levels, as follows:

20-40\% - Executive Leadership

$20 \%$ - Vice President;

$16 \%$ - Senior Principal;

$12 \%$ - Principal;

$8 \%$ - all other employees.

Titles have no meaning at TEOCO in the traditional sense of their relationship to a level of job responsibility. Rather, titles are determined on the basis of the employee's value to the company. There is a vice president, for example, who does not manage anyone.

In addition to bonuses, employees can purchase stock or receive stock options. At the initial founding of TEOCO in 1994, the only ownership vehicle was for employees to purchase stock outright. At the beginning of the company, Atul offered employees a specific number of shares to purchase, and he claims that every employee took full advantage of this opportunity. However, by 1999-2000, the value of the stock had risen to a level that Atul explains made it difficult for employees to purchase outright, so traditional stock options were awarded, instead of requiring employees to fully purchase the shares at the time of the grant. While acknowledging that options are necessary, Atul strongly believes that "option holders are not the same as shareholders," because he believes that the mere granting of options does not create ownership. 
With regard to purchasing stock, it should be noted that employees have the option of taking their annual bonus in stock up to a maximum of $60 \%$. The remaining $40 \%$ is intended for use in paying taxes.

The stock plan also provides for repurchase rights. If an employee terminates, the company has the right to repurchase the stock, with two exceptions. If an employee worked for the company for at least five years and owned the stock for a minimum of three years or if an employee worked for the company for ten years and owned the stock for at least a year, they may retain the stock, with the rationale that since they contributed many years of service to the success of the company, they should be able to continue to benefit. However, for others the stock is typically repurchased by the company.

Starting in January, 2007, the company decided to replace its 401K match with an ESOP. When the ESOP was implemented, it was both a bold and controversial decision. Atul came to the reluctant conclusion that if he wanted to create a broad-based ownership, an ESOP was needed as an involuntary mechanism. This was a difficult decision for him as it risked making existing employees unhappy, but he finally realized that it "was the only method to create broad-based ownership [because] educating and cajoling and encouraging was never going to work broadly enough."

His struggle with the ESOP was further complicated by the fact that Philip and John were not initially supportive. Their resistance delayed implementation for a year or two. This issue put the shared leadership model to a test; still, he said that even though he is the CEO, "there are times I know the right answer and they just don't see it, and I accept their decision." Only when these two had fully embraced it was the ESOP adopted. In the end, ESOP became very successful. While some employees were initially unhappy, they eventually saw how the TEOCO stock has outperformed the market since its inception in 2007.

Despite his belief in the need for the ESOP, Atul maintains that it does not create "ownership culture" in the same way that voluntarily investing one's own money to buy shares does. However, he wanted to achieve a broad-based ownership which, in his opinion, would not have been possible otherwise. From his perspective, ownership means wealth and the real benefit would be realized if the company was sold or went public. A successful and attractive company, especially one in the high tech field, can expect to sell at a high multiple of the price-toearnings ratio, which would result in an impressive return for employees, rewarding them for their exemplary performance and company loyalty.

\section{A Philosophy Of Total Compensation}

Atul's philosophy of compensation is that base salaries should be in the range of $0-10 \%$ below the going market rate. He believes that employees can accept this as a trade-off for a supportive and respectful work environment, a sizable bonus, along with the benefits of employee ownership. He even prefers it when a new employee takes a modest pay cut to join TEOCO, because he believes it is "a very resounding affirmation that they believe in our company and in our core values."

Atul: "We work our hardest if we are happier, if we enjoy our work and if we feel that we belong. That's why TEOCO has chosen to be an employee owned company; you don't work for an employer here, you work for yourself."

Since every TEOCO employee owns some company stock and receives an annual bonus and generous benefits, he feels that they are not underpaid. This full range of benefits seems to be highly valued and appreciated by employees. Hillary, for example, said that these make it difficult for her to consider leaving to work at another company. In comparing TEOCO's benefits with those her friends receive at other organizations, she is especially appreciative; three weeks instead of two weeks of vacation, the casual work environment and the flexible schedule were all cited.

Finally, TEOCO never misses an opportunity to recognize employees' commitment to the company, as well as their performance, by distributing awards. These awards reinforce the core values of the company: excellence, dedication and team work. It should be noted that these are peer-to-peer awards in which fellow 
employees are recognized for actions that exemplify one of the core values. [See Appendix 5 for an exhaustive list of TEOCO benefits and awards.]

\section{Human Resources As A Strategic Function}

In addition to shared leadership and employee ownership programs, the third component of TEOCO's competitive advantage is the way the senior executive team emphasizes the importance of managing TEOCO's main asset: its human resources. In many organizations, Human Resources is seen as a necessary cost of doing business; the HR function typically operates at a functional level or, at best in far fewer companies, at the executive level. ${ }^{8}$ At TEOCO, however, Atul has elevated HR to the strategic level. While there is a dedicated human resources director, Atul effectively serves as the organization's Chief Human Resources Officer.

For most organizations, the human resources policies and practices are transactional in nature. At TEOCO, the HR function has become the principal means of cultural transmission and reinforcement. In addition, Atul devotes strategic focus on HR because of his belief in the potential of an empowered work force. To some extent, part of the company's overall strategy is working from the "bottom up." The company relies on the abilities of its employees to understand what the market needs and develop new products. An example of how the empowered workforce functions at TEOCO was related by Dave [Software Architect]:

We are not structured in a way that we have a team for incubating products ... it's through conversations with our existing customers, generally, that the ideas for the next set of products come out.

Meanwhile, it is the shared leadership model that provides the opportunity for Atul to be so strongly and strategically focused on HR while depending on John, Faye and others to bring in the revenues. In an organization whose principal assets and competitive advantage are its human and intellectual capital, Atul and the shared leadership team have recognized the strategic importance of HR to its success.

The culture at TEOCO revolves singularly around the principle of employee ownership; it is embedded in the language, the policies and practices, the daily activities and even the rituals at TEOCO. There is a formal HR policy manual which is kept continuously current. While the manual is comprehensive in its scope, it is somewhat limited in specific details. Atul's stated philosophy of a policy manual is that "less is more," and the existing manual is larger than he would prefer. His rationale for not wanting to embed detailed procedures into the policy manual is that he prefers to have as few rules as possible. He believes that every employee will always want to do what is in the best interest of the company, and to reinforce the culture at TEOCO he believes that doing the right thing might at times require violating a policy.

TEOCO's articulated core values, and the resulting organizational culture, are evident in the working environment as well as in the HR policies and practices. The overall environment could be described as one of collegiality and mutual respect. Atul's background and beliefs support his desire for peace at the office, wanting employees to respect one another and not wanting employees to feel insecure about their jobs. Hillary validated this perception when she said "I think the environment is one of my favorite things about TEOCO." She claims that Atul comes by her office every week, and she thinks it is the same for many other employees as well. She described that "he walks around" and is very interactive. Brian independently said that "I get high-fives from Atul probably four days a week." He noted that many new employees, especially those who come from larger organizations, often comment on how surprised they are that the CEO recognizes them, let alone that they see him come down to their floor. Further, Brian mentioned that interpersonal relationships are very important at TEOCO. For many employees some of their best friends work there, and "that's a really big benefit that isn't on any paperwork or on any contract."

The socialization process at TEOCO begins at new employee orientation and is continuously reinforced through the HR policies and practices. Carrie (Director of HR) believes that the principal mission of HR is to help

\footnotetext{
${ }^{8}$ As Peter Drucker said, “All organizations now say routinely, 'people are our greatest asset.' Yet few practice what they preach, let alone believe it." "The New Society of Organizations," Harvard Business Review, Sept/Oct, 1992.
} 
shape employee perceptions, especially as it relates to employee ownership, and to impress upon every employee the core value of "driving for progress through ownership."

The HR policies and practices, themselves, demonstrate their critical importance through the resulting work environment. Taken together, the culture of employee ownership, combined with the strategic focus on HR, serve to recruit, motivate and retain the TEOCO workforce.

The importance of human assets to the company's success is highlighted by the active involvement of its $\mathrm{CEO}$ and chairman in the hiring process. He interviews every applicant before a hiring decision is made. As he says, "Nobody gets hired without meeting me, and nobody gets hired without getting my nod." The two areas in which he exercises tight-fisted control are hiring and cost management. He believes he has developed unique expertise to know "who to hire and what to look for." His focus is not only on technical competence, but on "cultural fit" as well. In many ways Atul could be described as the keeper of the culture. He gets so deeply involved in the hiring process that he says he is sometimes asked if he doesn't have anything better to do, and he responds by saying that there is nothing more important because the hiring process is so vital to the company's continued success.

\section{TA, TTI AND THE FUTURE OF TEOCO}

How will the story of TEOCO unfold with the investment by TA and the acquisition of TTI? From a purely business perspective, these decisions were justifiably necessary and defensible. However, each of the three distinctive characteristics of TEOCO's model of success, the shared leadership model, the culture of employee ownership and the resulting HR policies and practices, are being challenged in this post-acquisition environment.

\section{Impact On Shared Leadership}

The scope of the combined enterprise presents challenges that may strain the shared leadership model. TA's investment already added two influential directors to TEOCO's board. While directors usually have a "nose in, hands out" approach to management, the representatives of investment funds appointed to a company's board tend to be far more proactive in their "dialogues" with the senior team managing their investment. The subsequent acquisition of TTI added a fourth executive, Eitan Naor, into the leadership mix and in the last two years, Avi (TEOCO's CFO) has also become a key member of the Executive Leadership Team. Considering the distance between TEOCO and TTI, as well as their respective nearly equal sizes, it remains to be seen how the strengths and weaknesses of each leader will play out in the management of this new entity. For instance, Atul's well-recognized skills in hiring and motivating employees on a daily basis may not prove as beneficial or essential for TTI.

\section{Impact On The Culture Of Employee Ownership}

Avi claims that the cultures have nothing in common. Yet the senior management team seems adamant that the culture of TEOCO has not and will not change. Faye says, "I don't think there's been significant change." Still, she acknowledged the inevitability that an aggregated culture will arise in which each organization impacts the other. But she adds, "I can see [Atul] sitting in that chair right now saying, 'It's not going to happen."”

These statements are not surprising, as it is nearly universal that in this situation company executives proclaim that their acquisition will not change the corporate culture. Yet some degree of change is inevitable, and change has already occurred. These events will inevitably impact business activities and decision-making. The TTI acquisition and the investment of TA enhance the likelihood that within the next three years TEOCO may be acquired by a larger corporation, go public or require some other fundamental organizational realignment. Before agreeing to the TA investment, Atul says that he went to the employees for their consent. He believes the employees were comfortable with the transaction or he would not have done it; he says that the employees are aware of its positive impact as well as the potential outcome.

Atul is determined to continue on the same path as before these major events. He points out that a condition of TA's investment in TEOCO was that he retain the role of CEO because he is so essential to the culture of the 
company. The bank, as a condition of the loan for the purchase of TTI, had the same requirement. Meanwhile, Atul is intent on TA receiving a good return on their investment in TEOCO.

Atul: "But I will no longer do that with a sense of obligation; I will do that with a sense of joy. You know, if you do something out of joy, you do it differently than when you do it out of a sense of obligation."

An immediate impact is that these two events place a strain on employee ownership. The ownership mix shifted significantly with the TA investment. Prior to this equity transaction, Atul controlled $75 \%$ of the shares, while employees owned 25\% from all combined sources. Post-TA, the employee share was halved as they were offered approximately $60 \%$ liquidity on their previous ownership. Given Atul's ownership, and his intention to maintain a controlling interest in the company, coupled with TA's sizable equity stake, an issue that arises is whether there is any meaningful future opportunity to expand employee ownership. This is further compounded by the near doubling of the total number of employees.

An interesting paradox, according to Atul, is that despite the lower total employee ownership, there is a perception that the TA liquidity has strengthened the culture of ownership. He said that he "predicted that post-TA our payroll deductions [to purchase stock] would go down. It has increased ... because [the employees] see a success story," even though the stock purchase price has since increased. Atul attributes this pattern to the fact that employees witnessed other employees making significant sums of money from the TA transaction. He claims that now they truly understand and value ownership. As he says, "Once you've made money out of ownership, it changes you forever. And until you do, you don't believe it." Atul felt a very deep sense of gratitude to his long-term employees for their loyalty and sacrifice in creating value for TEOCO. The TA transaction allowed him to fulfill his commitment that one day they would get a return on their investment of time and money into TEOCO.

While these events will inevitably bring about changes in the way the company is managed, John believes that these will not dilute the culture. The TA investment "allowed TEOCO to preserve something that I think is pretty important to the way we operate, which is having employee ownership in the business, and that employees have a piece of it." A firm believer in employee ownership, he has "worked at the world's largest employee-owned company, for Telecordia, which was owned by SAIC." He claims that TEOCO is heavily modeled after SAIC in terms of employee ownership as a mechanism.

John: "If you're just paying people to show up to work and they get an annual bonus - those are two factors. But if you introduced the third factor of employee ownership - why wouldn't you treat that as a means to motivate the employees beyond just simply giving them a salary and giving them a bonus? ... And that's what Dr. Beyster [the founder of SAIC] figured out before anybody else figured it out."

These perceptions by senior management were validated by Carrie, HR Manager. When asked about the relatively small percentage of total stock owned by employees, she claims that the perception of employee ownership continues to be important, and that all employees still have opportunity to build additional equity. She cited, for example, that every new employee is granted a certain amount of ownership rights; they determine how much stock they want to purchase either through payroll deduction or the internal stock market. Brian validated this further when he said that once employees realize the benefits of being invested in the company, it changes their perspective. Like Atul, he underlined that this reality became clear for many employees when they witnessed others cashing out a portion of their equity with the TA investment. As he said, "Once that clicks in, it builds on it."

It remains to be determined if the employees of TTI will become owners, and whether they will embrace the culture of ownership. It is also uncertain how TEOCO's employee perceptions may change in terms of the growing price of ownership and the potential diminished opportunity for share availability.

\section{Impact On Human Resources As A Strategic Function}

The TTI acquisition will strain Atul's role as the organization's chief human resources officer and as someone who has been intimately and deeply involved in all HR-related decisions of the company. Dave describes Atul's current role in HR activities. 
Dave: "Atul is very, very, very engaged at the staffing and who's working on what and the hiring process. Its personnel stuff. Personnel and costs are the two things he focuses on...it blows my mind the level of detail and recollection he has on individual people and what's going on in the company."

As the company continues to grow, and as the complexity of issues expands, it will become increasingly difficult to maintain this level of involvement in details. A further challenge will be the issue of the standardization and consistency of application of HR-related policies and practices. Atul has a strong aversion to formal policies, preferring instead to have maximum flexibility and discretion in deciding HR issues.

Atul: "Life is all about making decisions and the reason management exists is to use judgment. Too many people want to make too many rules and they don't want to use judgment and I feel that if judgment doesn't exist then management doesn't have a job."

Given the increasingly litigious and regulated work environment for organizations, such a philosophy can create challenges for HR. When asked about Atul's philosophy of a policy manual where "less is more," HR Director Carrie admitted that there are some policies "that do cause me a little heartburn just because it's a little tough to administer without having something solid." One example she cited is that the sick leave policy is administered on an honor system. The only way to monitor abuse, she says, is indirectly by the impact such abuse may have on employee performance. As the company gets larger, she believes it would be easier if there were specific guidelines to turn to in a dilemma, to be able to say, "Here's the policy." Yet despite the lack of specifications, she claims there appears to be a high degree of consistency in the administration of HR policies.

Whether HR will continue to be viewed as a strategic function and receive the executive focus that it has had will be tested as well in the new corporate environment.

\section{Impact On TEOCO's Core Competencies}

While Atul believes that corporate culture and philosophy have played "key roles in our success", he says "that without its distinctive core competencies the company could not have been successful." Whether the core competencies that TEOCO has built can carry over in the post acquisition environment is an unanswered question. That TTI is similar in size to TEOCO and that they are geographically separated are two factors that will pose challenges in transferring specialized expertise from the acquiring company to the acquired company and vice versa. Also, given that the two companies had different cultures at the time of acquisition, additional work will have to be done to ensure successful transference of core competencies.

\section{CONCLUSION}

The challenge for any organization with a strong culture and a loyal workforce is to sustain them and adapt them in the face of organizational change. Over a very short period of time, TEOCO has changed its capital structure and expanded its business. How and to what extent TEOCO manages these changes will determine whether it maintains its competitive advantage and, finally, what will be its overall fate.

\section{ACKNOWLEDGEMENTS}

The authors would like to thank the employee owners of TEOCO who graciously shared their knowledge, experiences and perspectives about the company. Their viewpoints were invaluable in ensuring that this case provides a true representation of the culture and practices of the company.

\section{AUTHOR INFORMATION}

Thomas J. Calo is an Assistant Professor of Management in the Franklin P. Perdue School of Business at Salisbury University. He earned his doctorate degree at The George Washington University in Human and Organizational Learning. Prior to his academic career he was a senior Human Resource professional in both the private and public sectors. He worked in London, with broad European HR responsibilities, and is currently active in teaching Human 
Resource professionals in China. Prof. Thomas Calo, Ed.D., Perdue School of Business, Salisbury University, Salisbury, MD 21801. E-mail: tjcalo@ salisbury.edu. Corresponding author.

Olivier Roche is Assistant Professor of Management and international business in the Franklin P. Perdue School of Business at Salisbury University and Academic Director of the Corporate Governance program at McGill University, where he received his $\mathrm{PhD}$ in management. He is also a graduate from Georgetown University [Law School] and a licensed attorney in the State of New York. Prior to his academic career, he was an investment officer at the World Bank in Washington DC and an investment banker in Tokyo and Hong Kong. Prof. Olivier Roche, PhD, Perdue School of Business, Salisbury University, Salisbury, MD 21801. E-mail: oproche@ salisbury.edu

Frank Shipper (Ph.D. Utah) is Professor of Management and Chair of Management and Marketing in the Franklin P. Perdue School of Business at Salisbury University. His current teaching, consulting, and research interests are managerial/leadership skills development, and employee ownership and culture. His articles have appeared in the Academy of Management Journal, Organizational Dynamics, Leadership Quarterly, Human Relations, Academy of Management Learning \& Education, and others. He has been recognized by the Academy of Management and the Center for Creative Leadership for his work on management development. As a consultant, he assists organizations in developing and validating their management development processes. Prof. Frank Shipper, PhD, Perdue School of Business, Salisbury University, Salisbury, MD 21801. E-mail: fmshipper@ salisbury.edu 


\section{APPENDIX 1: BOARD OF DIRECTORS}

In addition to John Devolites, Philip M. Giuntini and Atul Jain, TEOCO's board is composed of a majority of outside board members with deep telecom industry expertise:

Gabriel Battista, Former Chairman, Talk America Gabe Battista formerly served as Chairman of the Board of Directors of Talk America, where he previously served as CEO. Prior to joining Talk America in January of 1999, Mr. Battista served as CEO of Network Solutions, Inc. Before joining Network Solutions, Mr. Battista served as CEO, President and COO of Cable \& Wireless, Inc. He also held management positions at US Sprint, GTE Telenet and The General Electric Company. He serves as a director of Capitol College, and Systems \& Computer Technology Corporation (SCTC).

Brian J. Conway, Managing Director, TA Associates Mr. Conway heads TA Associates' Boston office Technology Group, focusing on recapitalizations, buyouts and minority growth investments of technology-based growth companies. He is also a member of TA Associates' Executive Committee. Prior to joining TA Associates, Mr. Conway worked with Merrill Lynch in Mergers and Acquisitions and Corporate Finance. He serves on the Board of Directors for Epic Advertising, IntraLinks, and Numara Software.

Hythem T. El-Nazer, Senior Vice President, TA Associates Mr. El-Nazer's focus at TA Associates is on recapitalizations, management-led buyouts, and growth capital investments in telecommunications, media and other technology-based services companies. Prior to joining TA Associates, Mr. El-Nazer worked with McKinsey \& Company and Donaldson, Lufkin \& Jenrette - Investment Banking. He serves on the Board of Directors for eSecLending, Radialpoint, and is Board Observer at Orascom Telecom Holding S.A.E. and Weather Investments S.p.A.

Robert J. Korzeniewski, Former Executive Vice President, VeriSign As VeriSign's Executive Vice President, Corporate Development and Strategy, Mr. Robert Korzeniewski is responsible for providing a consistent strategy and focus for investments and merger-and-acquisition activity. Mr. Korzeniewski served from 1996-2000 as CFO of Network Solutions, Inc., which was acquired by VeriSign in June 2000. Mr. Korzeniewski came to Network Solutions from SAIC, where from 1987 to 1996, he held a variety of senior financial positions.

Source: TEOCO's website 
Journal of Business Case Studies - January/February 2012

Volume 8, Number 1

APPENDIX 2: INDUSTRY LANDSCAPE / MAJOR COMPETITORS

\begin{tabular}{|c|c|c|c|c|c|c|c|}
\hline \multicolumn{8}{|c|}{ 1) Least Cost Routing } \\
\hline & \multicolumn{5}{|c|}{--------------Regions-------------- } & \multicolumn{2}{|c|}{--Market Segments-- } \\
\hline Vendors & NA & CALA & EMEA & APAC & OVERALL & Mobile & PSTN \\
\hline Ascade & $\mathrm{P}$ & -- & NP & NP & $\mathrm{NP}$ & NP & NP \\
\hline Connective-Sol & NP & -- & -- & $\mathrm{P}$ & $\mathrm{P}$ & NP & $\mathrm{P}$ \\
\hline GCS & NP & -- & -- & NP & NP & NP & NP \\
\hline OrcaWave & NP & -- & $\mathrm{P}$ & $\mathrm{P}$ & $\mathrm{P}$ & $\mathrm{P}$ & NP \\
\hline Prime Carrier & $\mathrm{P}$ & -- & $\mathrm{P}$ & $\mathrm{P}$ & $\mathrm{P}$ & $\mathrm{P}$ & $\mathrm{P}$ \\
\hline Pulse Networks & NP & -- & -- & NP & NP & NP & NP \\
\hline Subex & -- & NP & -- & -- & -- & -- & -- \\
\hline Telarix & ML & $\mathrm{P}$ & ML & ML & ML & ML & ML \\
\hline \multicolumn{8}{|c|}{ 2) Revenue Assurance } \\
\hline & \multicolumn{5}{|c|}{-------------Regions------------- } & \multicolumn{2}{|c|}{--Market Segments-- } \\
\hline Vendors & NA & CALA & EMEA & APAC & OVERALL & Mobile & PSTN \\
\hline Connectiva & $\mathrm{P}$ & $\mathrm{P}$ & NP & NP & NP & NP & $\mathrm{NP}$ \\
\hline Connectiv & NP & -- & -- & -- & $\mathrm{P}$ & NP & $\mathrm{P}$ \\
\hline Cvidya & NP & -- & -- & NP & -- & -- & NP \\
\hline Razorsight & $\mathrm{P}$ & -- & -- & -- & $P$ & $P$ & $\mathrm{P}$ \\
\hline Subex & NP & $P$ & ML & ML & ML & ML & ML \\
\hline Qosmos & $\mathrm{P}$ & -- & $\mathrm{P}$ & $\mathrm{P}$ & $\mathrm{P}$ & $\mathrm{P}$ & $\mathrm{P}$ \\
\hline Wedo & NP & -- & ML & $\mathrm{NP}$ & ML & ML & ML \\
\hline \multicolumn{8}{|c|}{ 3) Cost Management } \\
\hline & \multicolumn{5}{|c|}{-------------Regions-------------- } & \multicolumn{2}{|c|}{--Market Segments-- } \\
\hline Vendors & NA & CALA & EMEA & APAC & OVERALL & Mobile & PSTN \\
\hline Connectiv & $\mathrm{P}$ & -- & -- & -- & $\mathrm{P}$ & $\mathrm{P}$ & $\mathrm{P}$ \\
\hline Martin Dawes & -- & -- & NP & -- & $\mathrm{P}$ & NP & $\mathrm{P}$ \\
\hline Razorsight & ML & -- & -- & -- & NP & NP & NP \\
\hline Subex & $\mathrm{P}$ & NP & ML & ML & ML & ML & ML \\
\hline
\end{tabular}

Note: Source TEOCO Marketing Department: NA = North America; CALA = Central America \& Latin America; EMEA =

Europe, Middle East and Africa; APAC = Asia \& Pacific. PSTN = Public Switched Telephone Network.

$P=$ has a presence in the market

$N P=$ has a notable presence in the Market

$M L=$ is a market leader 


\section{APPENDIX 3: TEOCO / TTI LEADERSHIP}

Atul Jain, Chairman and CEO: Atul Jain founded TEOCO Corporation in 1994. Prior to starting TEOCO Corporation, Mr. Jain was with a Silicon Valley firm called TIBCO for seven years. At TIBCO, Mr. Jain's focus was to work with Fortune 500 clients to design and build state-of-the-art software solutions leveraging the company's trademark TIB platform.

Philip M. Giuntini, Vice Chairman and President: Philip M. Giuntini joined TEOCO in February 2000 as Vice Chairman and President. Prior to joining TEOCO, Mr. Giuntini was President and on the Board of Directors of American Management Systems, Inc. (AMS), a \$1B international business and information technology consulting firm headquartered in Fairfax, Virginia.

John Devolites, Vice President and General Manager: John Devolites is currently the Vice President and General Manager at TEOCO focusing on solutions for the communications service provider industry. Previously, Mr. Devolites served as President of Professional Services for Telcordia. His other work experiences include executive positions at PricewaterhouseCoopers, E-Commerce Industries, Andersen, American Management Systems (AMS), Alexander Proudfoot PLC, and Booz Allen Hamilton.

Avi Goldstein, Chief Financial Officer (CFO): Avi Goldstein joined TEOCO in October 2008 and was nominated TEOCO's CFO on April 2009. Prior to joining TEOCO, Mr. Goldstein co-founded several startup companies as well provided consulting services in the Telecom arena with a strong focus on Mergers and Acquisitions. Prior to that Mr. Goldstein served as an Executive Vice President and CFO of ECtel Ltd. (NASDAQ: ECTX) from its establishment until 2005. Mr. Goldstein led ECtel to a successful IPO as well as private placements and M\&A activities.

Eitan Naor, General Manager and CEO of TTI: Eitan Naor joined TEOCO in August 2010 and brings more than 25 years of leadership and experience in the global telecom and service assurance markets. Prior to joining TEOCO, Mr. Naor served as President and CEO of Magic Software (NASDAQ:MGIC), where he led a significant restructure of the business and regained focus in its worldwide network of partners, resulting in a significant increase in sales and a return to profitability in less than one year. Mr. Naor also had great success in his other professional roles, including President and CEO of ECTEL (NASDQ:ECTX, Division President at AMDOCS, and Vice President with ORACLE Israel.

Source: TEOCO's website 


\section{APPENDIX 4: TEOCO'S CORE VALUES \& VALUE PROPOSITION}

At TEOCO, The Employee-Owned Company, we are driven by our core values. These values are our guiding principles in all business initiatives:

- Alignment with Employees, Clients and Community: We act in the best interest of our employees, clients and community, consistently seeking partnership and mutual benefit.

- Integrity, Honesty and Respect: We value our reputation and conduct our business with integrity, honesty and respect for each individual.

- $\quad$ Acting with Courage: We demonstrate a willingness to take risks, while conducting our business in a responsible manner.

- Drive for Progress through Ownership: We are committed to a relentless pursuit of excellence, never being satisfied with the status quo. We are a team whose sum is greater than its parts and devoted to constant innovation.

TEOCO sets standards of excellence that others strive to emulate in our areas of focus -- cost management, routing and revenue management. TEOCO's value proposition is as follows:

- Innovation: TEOCO's committed emphasis on one industry allows us unparalleled customer focus. We commit a significant share - up to $30 \%$ - of our annual revenues to research and development to address your precise needs.

- Stability: TEOCO is the only firm in our industry segment that is financially sound, debt free and employee owned. You can rest assured that we are responsive to your needs and will be there tomorrow.

- Integrity: At TEOCO, acting with integrity is one of our essential core values. We focus intensely on developing mutually beneficial, trust-based relationships with customers and communicating honestly in every situation.

- Deep Industry Expertise: Our team includes experienced professionals, many of whom have substantial telecommunications experience and/or have worked directly in service provider cost management organizations.

Source: TEOCO's website 


\section{APPENDIX 5: TEOCO's BENEFITS AND AWARDS}

Flexible Schedule: Flexible working hours occur on an informal basis and vary from job to job and department to department. While there is no formal HR policy on flexible working hours or working from home, this approach is consistent with its performance-driven culture in that what ultimately matters is employee performance. Even though employees may be permitted flexibility with schedules and working from home, employees are expected to be available nights, weekends and even vacations when there are pressing deadlines or problems to trouble-shoot.

Snacks and Beverages: Company-provided snacks, coffee and other beverages are made available throughout the day for all employees.

"Splash Vacation:" After completing five years of service (and on every subsequent fifth-year anniversary) employees are provided with an extra week of paid vacation. They are also provided with a reimbursement of up to $\$ 2,000$ for expenses incurred (transportation, lodging, etc.) in taking a vacation for themselves and their family to any place of their choosing.

ACE Award: ACE stands for Attitude, Commitment and Excellence. This is TEOCO's version of an "Employee of the Year" award, and is given annually to the employee who best exemplifies these three qualities. The winner, who receives stock and a cash award, is chosen by a committee which is comprised of previous winners of the ACE Award.

MVP Award: The Most Versatile Player Award, similar in concept to the ACE Award, is given annually to an employee who may not rise to that level of excellence, but who contributes to the organization in multiple ways. The winner receives stock and a cash award. Like the ACE Award, the winner is chosen without any management involvement, and the selection committee is comprised of previous winners of the award.

TEOCO Star Award: This is a peer-to-peer award in which employees recognize fellow employees for doing something that exemplifies one of the core values. This award would be TEOCO's version of a "spot bonus," with the exception that it is peer-to-peer rather than given by a supervisor. For example, one employee being helpful to another on a project might garner them a recommendation for the award. At the monthly "all-hands meeting," there is a drawing amongst all those nominated that month, and the winner receives a $\$ 150$ Amex gift card as well as official acknowledgement.

One-Year Service Award: All new employees, on their first anniversary of employment, are given a plant, a balloon and a card signed by other employees to acknowledge their first anniversary. 
NOTES 